\title{
The EUPHRATES trial (Evaluating the Use of Polymyxin B Hemoperfusion in a Randomized controlled trial of Adults Treated for Endotoxemia and Septic shock): study protocol for a randomized controlled trial
}

\author{
David J Klein ${ }^{1 *}$, Debra Foster ${ }^{2}$, Christa A Schorr ${ }^{3}$, Kazem Kazempour ${ }^{4}$, Paul M Walker ${ }^{2}$ and R Phillip Dellinger ${ }^{3}$
}

\begin{abstract}
Background: Septic shock is common and has unacceptably high morbidity, mortality, and associated cost with numerous failed attempts at developing effective therapies. Endotoxin, one of the most potent mediators of sepsis, is found in high levels in approximately $50 \%$ of patients with septic shock. Polymyxin B (PMX) hemoperfusion has been shown in numerous studies to successfully remove endotoxin and potentially improve outcomes. EUPHRATES (Evaluating the Use of Polymyxin B Hemoperfusion in a Randomized controlled trial of Adults Treated for Endotoxemia and Septic shock) is a theragnostic trial (matching blood measurement to treatment capability) of PMX hemoperfusion in patients with septic shock and confirmed endotoxemia as measured by the endotoxin activity assay (EAA).
\end{abstract}

Methods: EUPHRATES is a pivotal regulatory trial that is multi-centered, placebo-controlled and blinded. The trial is being conducted in fifty ICUs in the United States and Canada and is powered to enroll 360 patients. Patients with persistent septic shock despite adequate fluid resuscitation on vasopressors for more than 2 and less than 30 hours are eligible for measurement of the EAA. Those with EAA $\geq 0.60$ are eligible to be randomized to treatment with two sessions of PMX hemoperfusion 24 hours apart. The primary endpoint for the trial is 28-day all-cause mortality.

Discussion: Unique features of the trial include absence of systemic inflammatory response (SIRS) criteria as a requirement for inclusion, use of the EAA to confirm endotoxemia as a requisite for treatment, and use of a detailed "façade" hemoperfusion event as a blinding mechanism. The outcomes of the second interim analysis included a resizing of the trial to 650 patients and the addition of an exclusion criterion of subjects with multiple organ dysfunction score (MODS) $\leq 9$. Results are anticipated in 2016.

Trial registration: Clinicaltrials.gov identifier: NCT01046669. Registered: January 8, 2010.

Keywords: Endotoxin, Endotoxemia, Septic shock, Polymyxin-B, Hemoperfusion, Theragnostics

\footnotetext{
* Correspondence: kleind@smh.ca

'Department of Critical Care, and the Keenan Research Centre, Li Ka Shing Knowledge Institute, 4-054C Donnelly Wing, St Michael's Hospital, 30 Bond Street, Toronto, Ontario M5B 1 W8, Canada

Full list of author information is available at the end of the article
} 


\section{Background}

Despite great advances in our understanding of the pathophysiology of severe sepsis (sepsis associated with organ dysfunction) and septic shock (severe sepsis associated with need for vasopressors following adequate fluid resuscitation), attempts to translate these findings into novel treatments and improved outcomes for patients have been disappointing [1]. Mortality, morbidity, and costs associated with management of septic shock patients in ICUs are unacceptably high [2]. Even the most promising of potential new therapies targeting specific mediators of the host response have failed to demonstrate consistent benefit when tested in large multi-centered, randomized, controlled trials despite encouraging results in animals and earlier phase studies [3]. Reasons cited for these failures are wide ranging, but likely include poor patient selection for therapies due to the heterogeneous and syndromic definition of the disease state of sepsis using American College of Chest Physicians / Society of Critical Care Medicine consensus criteria as well as failure of these therapies when subjected to the design rigors and mandated mortality outcomes found in late phase regulatory pathway trials [4].

Endotoxin (lipopolysaccharide; LPS) is perhaps the best studied and one of the most potent initiators and mediators of the host response in sepsis. Studies measuring endotoxin levels in septic patients have consistently demonstrated three key findings. First, a dose-response relationship between endotoxin levels in septic patients and adverse outcomes including organ failure and death [5]; second, the presence of elevated levels of circulating endotoxin in some, but not all, patients with sepsis including some with Gram positive infections and other forms of sepsis likely through the mechanism of gut translocation $[5,6]$; and third, the persistence of endotoxemia often days into the course of the disease process of severe sepsis [7]. A variety of approaches have been tried to target endotoxin therapeutically including monoclonal antibodies to neutralize LPS, small molecule and other competitive inhibitors of the LPS receptor Toll-like receptor (TLR) 4 to block LPS signaling, use of specific molecules to enhance endotoxin deactivation and clearance, and extracorporeal devices to remove endotoxin [8]. In 1982, Ziegler and colleagues [9] first reported the successful treatment of a cohort of patients with Gram negative bacteremia and shock using a human antiserum raised against the Eschericia Coli J5 bacterium core LPS or endotoxin. A $17 \%$ absolute reduction in death was observed in a selected group of 212 patients [9]. Of note, a very high percentage of these subjects had Gram negative bacteremia (63\%), anticipated to correlate very highly with the presence of endotoxemia. Subsequently, two large projects both testing monoclonal antibodies targeting LPS in sepsis, HA-1A and E5, each demonstrated positive results in early phase studies [10,11] including a 1991 Ziegler and colleagues study [11] again demonstrating a $19 \%$ reduction in mortality in the subset of 200 patients with Gram negative bacteremia treated with HA-1A in a total sample of 543 patients. However, several large follow-up randomized controlled trials with both HA-1A as well as E5 were negative and neither drug was approved for clinical use in the United States [12,13]. More recently, additional attempts at neutralizing endotoxin to increase survival in severe sepsis utilizing (a) bactericidal/ permeability-increasing protein, (b) a lipid emulsion of recombinant HDL that binds endotoxin, (c) a small molecule TLR4 inhibitor (TAK242), and (d) E5564, a lipid A analogue and competitive inhibitor of TLR4, also all failed to show reduction in mortality in severe sepsis patients [14-16].

Polymyxin B (PMX) is a cyclic cationic polypeptide antibiotic derived from Bacillus polymyxa that has the ability to bind and neutralize endotoxin. Unfortunately, infusion of polymyxin in humans results in nephrotoxicity and neurotoxicity limiting its intravenous use to salvage therapy for Gram negative enterobacteriaciae resistant to other antibiotics [17]. A novel therapeutic strategy whereby PMX is adsorbed to a polystyrene fiber in a hemoperfusion device that is used to remove circulating endotoxin was developed in Japan in the late 1990s. A wide variety of small open-label clinical trials using this strategy in sepsis and other patient subtypes have been published with generally encouraging results. Cruz and colleagues [18] published a systematic review and meta-analysis of 28 trials using PMX direct hemoperfusion (PMX-DHP) to treat patients with severe sepsis and septic shock. Although there was heterogeneity amongst the trials largely done in Europe and Japan, across a total cohort of 978 patients treated with the therapy, improvements were noted in hemodynamics (mean arterial pressure) as well as oxygenation ( $\mathrm{PaO} 2 /$ FiO2 ratio, and there was a statistically significant improvement in risk of death (risk ratio $0.53,95 \%$ CI 0.43 to 0.65 ) [18]. More recently, in 2009, the Early Use of Polymyxin Hemoperfusion in Abdominal Septic Shock (EUPHAS) trial [19], a randomized but unblinded study of 64 patients in 10 tertiary Italian ICUs, demonstrated statistically significant improvements in the primary endpoints of hemodynamics and organ dysfunction. Also, the absolute risk of death at 28 days improved significantly from $53 \%$ in the conventional therapy group to $32 \%$ in the PMX-DHP treated group [19]. This result, albeit encouraging, is considered controversial as the trial was stopped early after an interim analysis showed the mortality difference in a secondary endpoint. In addition, the trial was not blinded [20]. Patients were selected for therapy based on evidence of septic shock from an intra-abdominal 
source to hopefully enrich the patient population, but endotoxin levels were not measured prior to enrollment a common theme in all the previously discussed trials attempting to neutralize endotoxin with drug therapy. Thus, there have been widespread calls for a definitive randomized controlled trial on this promising but not widely accepted therapy in North America [20].

Here, we present the protocol for, and discuss the design, of the "Evaluating the Use of Polymyxin B Hemoperfusion in a Randomized controlled trial of Adults Treated for Endotoxemia and Septic shock (EUPHRATES)" trial. We believe it to be the first blinded and randomized controlled, diagnostic-directed trial of a hemoperfusion device ever done in sepsis. We hypothesize that targeted treatment of patients with septic shock and high levels of circulating endotoxin as confirmed by the endotoxin activity assay (EAA) combined with directed therapy in the form of PMX-DHP endotoxin removal, will result in a significant reduction in 28-day all-cause risk of death.

\section{Methods and design \\ Study design and outcomes}

The ongoing EUPHRATES trial (Clinicaltrials.gov identifier: NCT01046669) is a North American pivotal (under Investigational Device Exemption (IDE) from the United States Food and Drug Administration (FDA)) doubleblinded theragnostic trial of PMX-DHP therapy in adult patients with septic shock and confirmed endotoxemia as measured by EAA. The trial began in June 2010 and is scheduled to be completed by the end of 2016. Ethics approval for the trial protocol has been obtained from the research ethics board responsible for each site prior to starting the trial. A list of all ethical bodies that reviewed and approved the trial is listed in Table 1 . The primary outcome of the trial is 28-day all-cause mortality. The total number of patients estimated to be included in the study was planned as 360 from 50 ICUs in the United States and Canada. Consecutive patients with evidence of septic shock as indicated by initiation of intravenous antibiotics and on vasopressor therapy for hypotension will be screened and those eligible will be consented for a blood draw for measurement of EAA. The consort diagram is shown in Figure 1. Those with an EAA $\geq 0.60$ (high endotoxin activity level) will be considered eligible and consented for randomization to potential treatment with PMX-DHP or the control group. Otherwise, eligible patients with an EAA $<0.60$ after up to two blood draws 4 to 6 hours apart will be not be randomized but will be followed using a minimal dataset for mortality at 28 days in an observational cohort study. It is estimated that approximately $50 \%$ of otherwise eligible patients will have an EAA $\geq 0.60$. Table 2 summarizes the inclusion and exclusion criteria for EUPHRATES. Note that a patient with any type of infection producing septic shock is eligible to be enrolled if high endotoxin activity is present (EAA $\geq 0.60$ ) as endotoxemia is not limited to Gram negative infection only (likely gut-derived endotoxin from translocation in non-Gram negative bacterial shock). In addition to the primary outcome measure of 28-day all-cause mortality, secondary outcomes include 90day, 6-month and 1-year all-cause mortality. Hemodynamic outcomes will be followed using the cumulative vasopressor index (Table 3) and other organ failure outcomes will be captured as both total and component scores of the multiple organ dysfunction score (MODS) [21,22]. Renal outcomes will be tracked using the Acute Kidney Injury (AKIN) criteria [23]. A full list of secondary and exploratory objectives is listed in Table 4.

\section{Participants}

Participants aged $\geq 18$ years old with septic shock and high endotoxin activity (EAA $\geq 0.60$ ) are eligible for the study. Written informed consent is obtained from each patient or their substitute decision maker prior to randomization. Septic shock is defined as a documented or suspected infection as indicated by either directed or empiric use of antibiotics and presence of hypotension of at least 2 hours duration requiring ongoing vasopressor support despite a fluid challenge of $30 \mathrm{ml} / \mathrm{kg}$ in the previous 24 hours. Subjects must also have at least one additional organ failure as defined by oliguria, thrombocytopenia, or need for mechanical ventilation. There is no requirement for subjects to meet any systemic inflammatory response syndrome criteria. Subjects with end-stage renal disease on dialysis are not eligible. The estimated 28-day mortality in this cohort of patients as per the Surviving Sepsis Campaign (SSC) database estimate is $35 \%$ [24].

Investigators agree to managing patients in line with the SSC guidelines [25,26]. There are no specific management requirements; however, as indicators of overall adherence to SSC guidelines and good clinical practices, two quality measures are being monitored.

\section{Study procedures \\ Coordination and randomization}

A clinical coordinating center (C4) at Cooper University Hospital, Camden, NJ, USA, has been established to confirm subject eligibility for the study and provide support to investigators and study personnel throughout the study period. The $\mathrm{C} 4$ consists of four members to evaluate eligibility (sepsis members) and two nephrologists (nephrology members) who provide treatment-related support. Subjects approved for randomization based on meeting full eligibility criteria including an EAA $\geq 0.60$ will be randomized. Randomization will be 1:1 using random block sizes of two and four. Research pharmacists will dispense identical boxes containing either treatment 
Table 1 Institutional Review Board information for EUPHRATES SDI-PMX-NA001 (EUPHRATES) site IRB list

Site\# IRB Chair

Site \#01 Louis Zeiger, MD

Site \#02

Theodore D Schultz

Site \#04 (site closed) James Linakis

Site \#05

Site \#06

Site \#07

Site \#08

Site \#09

Site \#10

Site \#11

Site \#12

Glenn Markenson,MD and Rick Granowitz, MD

Site \#13

\section{IRB address}

Cooper Health System

Institutional Review Board

Three Cooper Plaza Suite 504 Camden, NJ 08103

Western Institutional Review Board

12 Jul 2010

3535 Seventh Ave. SW

Olympia, WA 98502

Lifespan Office Research Administration Committee on the Protection of Human Subjects

17 Sep 2010

Rhode Island Hospital Institutional Review Board

593 Eddy St - Aldrich, 5 Providence, Rhode Island 02903

Institutional Review Board

04 Mar 2011

Office for Human Research Protection

201 Building, Room 4-60

200 First Street S.W.

Rochester, Minnesota 55905

The Committee for the Protection of Human Subjects

21 Dec 2010

6410 Fannin St., Suite 1100

Houston, TX 77030

Institutional Review Board

16 Aug 2010

621 S. New Ballas, Suite 6002

St. Louis, Mo. 63141

Western Institutional Review Board

29 Nov 2010

3535 Seventh Ave. SW

Olympia, WA 98502

Institutional Review Board/Privacy Board (IRB/PB)

14 Dec 2010

Memorial Sloan Kettering Cancer Center

1275 York Avenue

New York, NY 10065

Office of Regulatory Affairs

13 Dec 2010

Institutional Review Board

987830 Nebraska Medical Center

Omaha, NE 68198-7830

Human Subjects Protection Program

22 Nov 2010

1618 E. Helen Street

The University of Arizona

PO Box 245137

Tucson, AZ 85724

Baystate Medical Center

15 Dec 2010

Institutional Review Board

759 Chestnut Street

Springfield, MA 01199

Western Institutional Review Board 
Table 1 Institutional Review Board information for EUPHRATES (Continued)

\begin{tabular}{|c|c|c|c|}
\hline & & 3535 Seventh Ave. SW & \\
\hline & & Olympia, WA 98502 & \\
\hline \multirow[t]{3}{*}{ Site \#16 } & Theodore D Schultz & Western Institutional Review Board & 04 April 2011 \\
\hline & & 3535 Seventh Ave. SW & \\
\hline & & Olympia, WA 98502 & \\
\hline \multirow[t]{3}{*}{ Site \#17 (site closed) } & Theodore D Schultz & Western Institutional Review Board & 11 Apr 2011 \\
\hline & & 3535 Seventh Ave. SW & \\
\hline & & Olympia, WA 98502 & \\
\hline \multirow[t]{3}{*}{ Site \#19 } & Craig Scoville, MD, PhD & Eastern Idaho Regional Medical Center IRB & 14 Mar 2011 \\
\hline & & 3100 Channing Way & \\
\hline & & Idaho Falls, ID 83404 & \\
\hline \multirow[t]{3}{*}{ Site \#20a and 20b } & Mike Caligiuri & University of California San Diego & 27 Oct 2011 \\
\hline & & 9500 Gilman Drive & \\
\hline & & La Jolla, California 92093 & \\
\hline \multirow[t]{5}{*}{ Site \#21 } & Jennifer Weinman, BA, MA & Washington University in St. Louis & 21Feb 2012 \\
\hline & & Human Research Protection Office & \\
\hline & & 660 South Euclid Avenue & \\
\hline & & Campus Box 8089 & \\
\hline & & St. Louis, MO 63110 & \\
\hline \multirow[t]{3}{*}{ Site \#22 } & J Bruce Smith, MD, CIP & Thomas Jefferson University Hospital & 20 Oct 2011 \\
\hline & & 111 S. 11th Street & \\
\hline & & Philadelphia, PA 19107 & \\
\hline \multirow[t]{3}{*}{ Site \#23a } & Theodore D Schultz & Western Institutional Review Board & 29 Sep 2011 \\
\hline & & 3535 Seventh Ave. SW & \\
\hline & & Olympia, WA 98502 & \\
\hline \multirow[t]{5}{*}{ Site \#23b } & Manoo Bhakta, MD & College of Medicine, Chattanooga & 5 Jul 2012 \\
\hline & & Scientific Review Board & \\
\hline & & 960 East Third Street & \\
\hline & & Suite 102 & \\
\hline & & Chattanooga, TN 37403 & \\
\hline \multirow[t]{3}{*}{ Site \#25 (site closed) } & John T Promes, MD & Orlando Health & 20 Jan 2012 \\
\hline & & 1414 Kuhl Avenue & \\
\hline & & Orlando, FL 32806 & \\
\hline \multirow[t]{4}{*}{ Site \#26 } & SKM Kimber, MD, FRCPC & Health Research Ethics Board & 9 Jan 2012 \\
\hline & & 308 Campus Towers & \\
\hline & & University of Alberta & \\
\hline & & Edmonton, Alberta, Canada T6G 1 KB & \\
\hline \multirow[t]{4}{*}{ Site \#27 (site closed) } & Pamela J Oatis, MD & Research Oversight and Education & 29 Feb 2012 \\
\hline & & Mercy St. Vincent Medical Center & \\
\hline & & 2213 Cherry Street & \\
\hline & & Toledo, OH 43608 & \\
\hline \multirow[t]{4}{*}{ Site \#28 (site closed) } & Lois Colliler & Sharp Corondado & 18 Apr 2012 \\
\hline & & Sharp Memorial Hospital & \\
\hline & & 5555 Gossmont Center & \\
\hline & & La Mesa, CA 91942 & \\
\hline
\end{tabular}


Table 1 Institutional Review Board information for EUPHRATES (Continued)

\begin{tabular}{|c|c|c|c|}
\hline \multirow[t]{3}{*}{ Site \#29a } & \multirow[t]{3}{*}{ Russell Bjork, MD } & Memorial Health System & \multirow[t]{3}{*}{27 Mar 2012} \\
\hline & & 1400 East Boulder & \\
\hline & & Colorado Springs, CO 80909 & \\
\hline \multirow[t]{3}{*}{ Site \#29b } & \multirow[t]{3}{*}{ Russell Bjork, MD } & Memorial Health System & \multirow[t]{3}{*}{26 Oct 2012} \\
\hline & & 1400 East Boulder & \\
\hline & & Colorado Springs, CO 80909 & \\
\hline \multirow[t]{3}{*}{ Site \#30 } & \multirow[t]{3}{*}{ Philip C Hébert, MD PhD FCFPC } & Research Ethics Office, Room C819 & \multirow[t]{3}{*}{11 Sep 2012} \\
\hline & & 2075 Bayview Avenue & \\
\hline & & Toronto, ON Canada M4N 3 M5 & \\
\hline \multirow[t]{3}{*}{ Site \#31 } & \multirow[t]{3}{*}{ JD Miller, MD } & System Center-Hazard & \multirow[t]{3}{*}{11 Apr 2012} \\
\hline & & 100 Airport Gardens Road & \\
\hline & & Hazard, KY 41701 & \\
\hline \multirow[t]{4}{*}{ Site \#32 } & \multirow[t]{4}{*}{ Steven Kushner, MD } & Helen F. Graham Cancer Center \& Research Institute & \multirow[t]{4}{*}{$01 \mathrm{Jul} 2013$} \\
\hline & & West Pavilion - Suite 2350 & \\
\hline & & 4701 Ogletown-Stanton Road & \\
\hline & & Newark, Delaware 19713 & \\
\hline \multirow[t]{4}{*}{ Site \#33 } & \multirow[t]{4}{*}{ John Hafner Jr, MD } & Institutional Review Board & \multirow[t]{4}{*}{27 Jun 2012} \\
\hline & & One Illini Drive & \\
\hline & & Box 1649 & \\
\hline & & Peoria, IL 61656-1649 & \\
\hline \multirow[t]{4}{*}{ Sites \#34a and \#34b } & \multirow[t]{4}{*}{ Vivek Singh, MD } & Institutional Review Board Office & \multirow[t]{4}{*}{09 Aug 2012} \\
\hline & & Mail Code 7830 & \\
\hline & & 7703 Floyd Curl Dr. & \\
\hline & & San Antonio, TX 78229-3900 & \\
\hline \multirow[t]{5}{*}{ Sites \#35a and \#35b } & \multirow[t]{5}{*}{ Raphael Saginur, MD } & Ottawa Hospital Research Ethics Board & \multirow[t]{5}{*}{30 Aug 2012} \\
\hline & & 725 Parkdale Ave. & \\
\hline & & Civic Box 411 & \\
\hline & & LOEB Building & \\
\hline & & Ottawa, ON K1Y 4E9 & \\
\hline \multirow[t]{3}{*}{ Site \#36 } & Allen Korenbilt, MD, CIP & Rush University Medical Center & 31 Oct 2012 \\
\hline & & 1653 West Congress Parkway & \\
\hline & & Chicago, IL 60612-3833 & \\
\hline Site \#37 & Theodore D Schultz & Western Institutional Review Board & 17 Sep 2012 \\
\hline & & 3535 Seventh Ave. SW & \\
\hline & & Olympia, WA 98502 & \\
\hline Site \#38 & Theodore D Schultz & Western Institutional Review Board & 24 Jan 2013 \\
\hline & & 3535 Seventh Ave. SW & \\
\hline & & Olympia, WA 98502 & \\
\hline Site \#39 & Leonardo Tamariz, MD, MPH & Human Studies Subcommittee & 19 Sep 2012 \\
\hline & & Miami VA Healthcare System & \\
\hline & & 1201 Northwest 16th St. & \\
\hline & & Miami, FL 33125-1693 & \\
\hline Site \#40 & Theodore D Schultz & Western Institutional Review Board & 17 Jan 2013 \\
\hline & & 3535 Seventh Ave. SW & \\
\hline & & Olympia, WA 98502 & \\
\hline
\end{tabular}


Table 1 Institutional Review Board information for EUPHRATES (Continued)

\begin{tabular}{|c|c|c|c|}
\hline \multirow[t]{4}{*}{ Site \#42 } & Jeffrey Silverstein, MD, CIP; & Icahn School of Medicine at Mount Sinai & 01 Feb 2013 \\
\hline & Glenn Martin, MD, CIP; & One Gustave L. Levy Place & \\
\hline & Ilene Wilets, PhD, CIP & Box 1081 & \\
\hline & & New York, NY 10029-6574 & \\
\hline \multirow[t]{3}{*}{ Site \#43 } & John Montogomery, Chair & Lakeridge Health & 04 Apr 2013 \\
\hline & & 1 Hospital Ct. & \\
\hline & & Oshawa, ON, Canada L1G 2B9 & \\
\hline \multirow[t]{3}{*}{ Site \#44 } & SKM Kimber, MD, FRCPC & 308 Campus Tower & 27 Feb 2013 \\
\hline & & University of Alberta & \\
\hline & & Edmonton, AB T6G 1 K8 & \\
\hline \multirow[t]{3}{*}{ Site \#45 } & Franck Molin, MD & IUCPQ & 15 Apr 2013 \\
\hline & & 2725, Chemin Sainte-Foy & \\
\hline & & Quebec, QC G1V 4G5 & \\
\hline \multirow[t]{3}{*}{ Site \#46 } & Alan Lichtin & Cleveland Clinic Foundation & 05 Mar 2013 \\
\hline & & 9500 Euclid Ave. & \\
\hline & & Cleveland, OH 44195 & \\
\hline \multirow[t]{4}{*}{ Site \#48 } & Timothy Roehrs, PhD & Henry Ford Health System Research Administration & 01 Apr2013 \\
\hline & & 2799 West Grand Blvd & \\
\hline & & CFP-bsmt, room 46 & \\
\hline & & Detroit, Ml 48202 & \\
\hline \multirow[t]{5}{*}{ Site \#49 } & Stacey A. Page, PhD, Chair, CHREB & Conjoint Health Research Ethics Board (CHREB) & 10 Sep 2013 \\
\hline & & Research Services Office & \\
\hline & & 3rd Floor Mackimmie Library Tower (MLT 300) & \\
\hline & & 2500 University Dr., NW & \\
\hline & & Calgary, AB, Canada T2N 1 N4 & \\
\hline \multirow[t]{5}{*}{ Site \#51 } & Ronald Heslegrave, PhD & Mount Sinai Hospital & $03 \mathrm{Jul} 2013$ \\
\hline & & Research Ethics Board & \\
\hline & & 600 University Ave. & \\
\hline & & Room 19-311 & \\
\hline & & Toronto, ON, Canada M5G 1X5 & \\
\hline \multirow[t]{5}{*}{ Site \#52a and \#52b } & Karen McRae, MD, Co-Chair/Multidisciplinary & University Health Network (UHN) & 15 Apr 2013 \\
\hline & UHIN REB & Research Ethics Board (REB) & \\
\hline & & 10th Floor, Room 1056 & \\
\hline & & 700 University Ave. & \\
\hline & & Toronto, ON, Canada M5G 1 Z5 & \\
\hline \multirow[t]{3}{*}{ Site \#53 } & R Bert Wilkins & Western Institutional Review Board & $22 \mathrm{Jul} 2013$ \\
\hline & & 3535 Seventh Ave. SW & \\
\hline & & Olympia, WA 98502 & \\
\hline \multirow[t]{4}{*}{ Site \#54 } & L Wiley Nifong, MD & UMCIRB & 12 Feb 2014 \\
\hline & & East Carolina University & \\
\hline & & Brody School of Medicine, Brody 4 N-70 & \\
\hline & & Greenville, NC 27834 & \\
\hline \multirow[t]{3}{*}{ Site \#55 } & Rhodes L Rigsby, MD & Institutional Review Board & 05 Sep 2013 \\
\hline & & Research Protection Programs & \\
\hline & & 24887 Taylor St. & \\
\hline
\end{tabular}


Table 1 Institutional Review Board information for EUPHRATES (Continued)

\begin{tabular}{|c|c|c|c|}
\hline & & Suite 202 & \\
\hline & & Loma Linda, CA 92350 & \\
\hline \multirow[t]{5}{*}{ Site \#56 } & David Spiegel, MD & Stanford University Research & 12 Jun 2012 \\
\hline & & Compliance Office & \\
\hline & & 1501 South California Ave. & \\
\hline & & MC: 5579 & \\
\hline & & Palo Alto, CA 94304 & \\
\hline \multirow[t]{4}{*}{ Site \#57 } & Ike Eriator, MD & University of Mississippi Medical Center & 12 Feb 2013 \\
\hline & & Institutional Review Board & \\
\hline & & 2500 North State St. & \\
\hline & & Jackson, MS 39216-4505 & \\
\hline \multirow[t]{4}{*}{ Site \#58 } & Michael Geisser, PhD, Co-Chair & University of Michigan, IRBMED & 7 Mar 2014 \\
\hline & & 2800 Plymouth Road & \\
\hline & & Building 520, Room 3214 & \\
\hline & & Ann Arbor, Ml 48109-2800 & \\
\hline
\end{tabular}

cartridge boxes or sham boxes based on a serial number code linked to the randomization scheme. The sepsis $\mathrm{C} 4$ members are blinded to treatment allocation while the nephrology C4 team can be unblinded as needed.

\section{Timing}

To be eligible for treatment, following a minimum fluid challenge, patients must be in septic shock and on vasopressors at the specified dose levels in Table 2 for at least 2 hours continuously and not for more than 30 hours. A sample timeline for consent, measurement of EAA, and randomization are shown in Figure 2. The first treatment must be initiated within 24 hours of the EAA consent and the second approximately 22 hours after the first treatment. A sample timeline for the intervention period is shown in Figure 3.

\section{Measurement of endotoxin activity assay}

The EAA received $510(\mathrm{k})$ de novo clearance from the FDA in 2003 for the measurement of clinical samples for endotoxemia and to assess patients for risk of severe sepsis. The assay is semi-quantitative and values are expressed as EAA units between 0 and 1. A low EAA level is considered to be $<0.40$, intermediate level 0.40 to 0.59 , and high level $\geq 0.60$ (Spectral Diagnostics Inc., Toronto, Ontario, Canada). These cutoffs were established based on the results of the MEDIC trial [5]. The details of how to perform the assay are published elsewhere [27]. In the current trial, samples are run in duplicate by trained personnel. A correlation value of $15 \%$ or better is required for EAA results less than $<0.20$, and $20 \%$ for all other EAA results. If a patient is otherwise eligible but the EAA is below the high threshold of 0.60, a follow-up

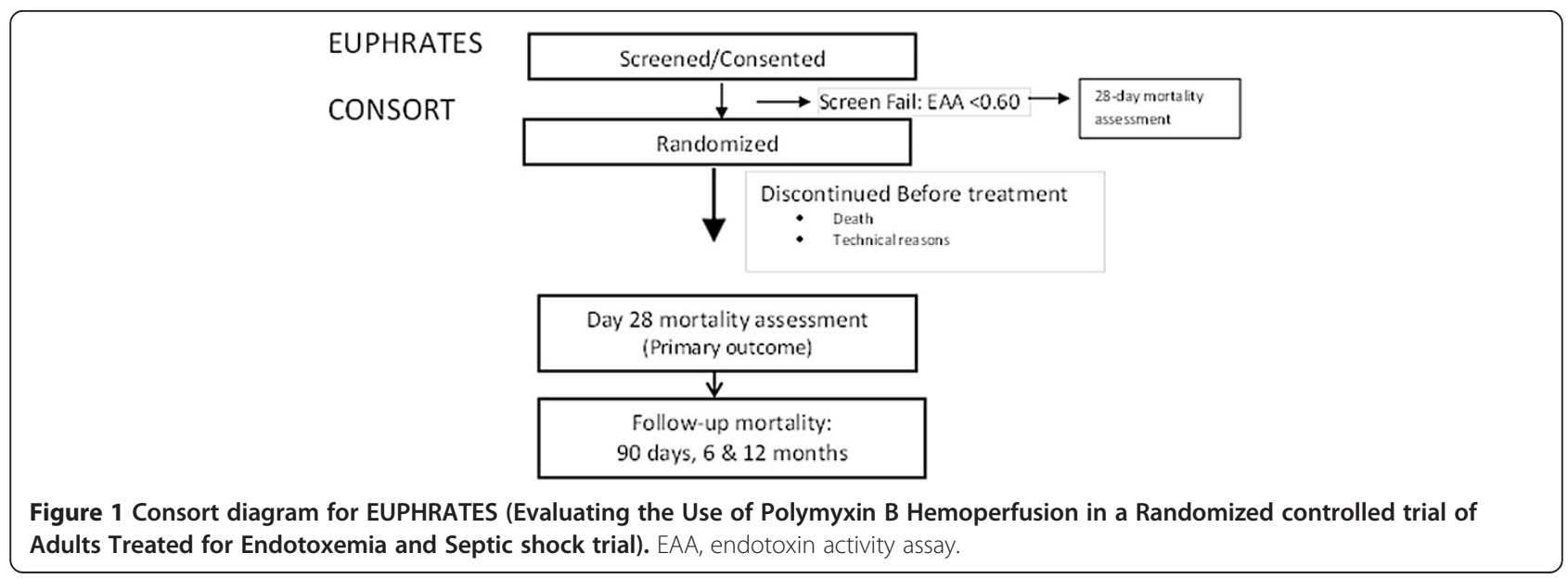


Table 2 Summary of inclusion and exclusion criteria

Inclusion criteria

Subjects who meet the following criteria (and have a signed informed consent) will be allowed into the study:

1. Age $\geq 18$ years of age

2. Hypotension requiring vasopressor support: Requirement for at least one of the vasopressors listed below, at the dose shown below, for at least 2 continuous hours and no more than 30 hours

a. Norepinephrine $>0.05 \mu \mathrm{g} / \mathrm{kg} /$ minute

b. Dopamine $>10 \mu \mathrm{g} / \mathrm{kg} /$ minute

c. Phenylephrine $>0.4 \mu \mathrm{g} / \mathrm{kg} /$ minute

d. Epinephrine $>0.05 \mu \mathrm{g} / \mathrm{kg} / \mathrm{minute}$

e. Vasopressin $>0.03$ units/minute

f. Vasopressin (any dose) in combination with another vasopressor listed above

3. The subject must have received intravenous fluid resuscitation of a minimum $30 \mathrm{~mL} / \mathrm{kg}$ administered within 24 hours of eligibility

4. Documented or suspected infection defined as definitive or empiric intravenous antibiotic administration

5. Endotoxin activity assay $\geq 0.60$

6. Evidence of at least one of the following criteria for new onset organ dysfunction that is considered to be due to the acute illness

a. Requirement for positive pressure ventilation via an endotracheal tube or tracheostomy tube

b. Thrombocytopenia defined as acute onset of platelet count $<150,000 \mu / L$

c. Acute oliguria defined as urine output $<0.5 \mathrm{ml} / \mathrm{kg} / \mathrm{hour}$ for at least 6 hours despite adequate fluid resuscitation or a reduction of $50 \%$ from prior known levels

\section{Exclusion criteria}

1. Inability to obtain an informed consent from the subject, family member or an authorized surrogate

2. Lack of commitment for full medical support

3. Inability to achieve or maintain a minimum mean arterial pressure of $\geq 65 \mathrm{mmHg}$ despite vasopressor therapy and fluid resuscitation

4. Subject has end-stage renal disease and requires chronic dialysis

5. There is clinical support for non-septic shock such as

a. Acute pulmonary embolus

b. Transfusion reaction

c. Severe congestive heart failure (for example, New York Heart Association Class IV, ejection fraction <35\%)

6. Subject has had chest compressions as part of cardiopulmonary resuscitation this hospitalization without immediate return to communicative state

\section{Subject has had an acute myocardial infarction within the past 4 weeks}

8. Subject has uncontrolled hemorrhage (acute blood loss requiring $>3$ Units of Packed red blood cellsin the past 24 hours)

9. Major trauma within 36 hours of screening

10. Subject has severe granulocytopenia (leukocyte count $<500$ cells $/ \mathrm{mm}^{3}$ ) or severe thrombocytopenia (platelet count $<30,000$ cells $/ \mathrm{mm}^{3}$ )

11. HIV infection in association with a last known or suspected CD4 count of $<50 / \mathrm{mm}^{3}$

12. Subject's baseline state is non-communicative

13. Subject has sustained extensive third-degree burns within the past 7 days

14. Body weight $<35 \mathrm{~kg}$

15. Known hypersensitivity to polymyxin B

16. Subject has known sensitivity or allergy to heparin or has a history of heparin associated thrombocytopenia

17. Subject is currently enrolled in an investigational drug or device trial 18. Subject has been previously enrolled in the current trial

19. Any other condition, that in the opinion of the investigator, would preclude the subject from being a suitable candidate for enrolment, such as end stage chronic illness with no reasonable expectation of survival to hospital discharge

20. Multiple Organ Dysfunction Score $\leq 9 * *$ - added post-second interim analysis

test may be done once, 4 to 6 hours after the first test, to reassess for potential eligibility.

\section{Description of the study intervention}

Patients assigned to the treatment arm who do not already have access for dialysis will have a standard hemodialysis catheter inserted in one of the femoral veins by an unblinded physician not involved in the clinical care of the patient. For those patients not assigned to the treatment arm, a "cut" hemodialysis catheter and associated dressing will be affixed to the skin in the femoral position to simulate a newly inserted line. The same physician that would have inserted the catheter stays in the room behind a curtain for a similar amount of time as would have been predicted for catheter insertion. At the conclusion of each hemoperfusion session, a standard opaque dressing will be placed over the line site to maintain the blind. After the second hemoperfusion session, 
Table 3 Cumulative vasopressor index

\begin{tabular}{ccccc}
\hline Vasopressor & $\begin{array}{c}\text { Dose } \\
\text { Range } \\
\text { 1 point }\end{array}$ & Dose Range & Dose Range & $\begin{array}{c}\text { Dose } \\
\text { Range }\end{array}$ \\
\hline $\begin{array}{c}\text { Dopamine } \\
\text { (mcg/kg/min) }\end{array}$ & 0 dose $\leq 5$ & $5<$ dose $\leq 10$ & $10<$ dose $\leq 15$ & $>15$ \\
Epinephrine & - & $0<$ dose $<0.05$ & $0.05<$ dose $<0.1$ & $>0.1$ \\
(mcg/kg/min) & & & & \\
Norepinephrine & - & $0<$ dose $<0.05$ & $0.05<$ dose $<0.1$ & $>0.1$ \\
(mcg/kg/min) & & & & \\
$\begin{array}{l}\text { Phenylephrine } \\
\text { (mcg/kg/min) }\end{array}$ & - & $0<$ dose $<0.4$ & $0.4<$ dose $<0.8$ & $>0.8$ \\
Vasopressin & - & & & Any \\
(units/min) & & & & dose \\
\hline
\end{tabular}

the hemodialysis catheter is removed and a standard opaque dressing applied over the region. In some patients the decision for dialysis has been made contemporaneously with the consent for study and in that case a dialysis catheter will be inserted and the treatment blinded only.

The PMX hemoperfusion column used in the study was developed in Japan and is manufactured by Toray Industries (Tokyo, Japan). The PMX treatment will be administered twice using two cartridges with the treatments completed approximately 24 hours apart. Each treatment will last for approximately 2 hours, at a blood flow rate of approximately $100 \mathrm{ml} /$ minute through the circuit (range of 80 to $120 \mathrm{ml} /$ minute). For the current trial, a standard intermittent hemodialysis machine will be used as a blood pump to administer the treatment. At the discretion of the unblinded nephrologist on the hemoperfusion team, anticoagulation, using intravenous unfractionated heparin, will be administered to maintain patency of the circuit for the duration of each 2-hour treatment. Patients already on anticoagulation for other indications or those with coagulopathy will not be anticoagulated further at the discretion of the nephrologist on the hemoperfusion team. Citrate anticoagulation is not allowed as per the recommendations of the manufacturer.

\section{Blinding}

The trial is blinded. For those patients assigned to the control arm, a simulated or "sham" hemoperfusion event is carried out to coincide with the timing of the treatment events in the other arm. In addition, a "cut" line is placed on the skin to simulate the presence of an indwelling central line. To maintain the trial's blind, the ICU physician investigators, those health-care professionals involved in recording blinded data, and those who are involved in data analysis, will remain blinded to allocation of treatment.

A nephrology staff member, the study coordinator, the ICU bedside nurse, and a pharmacist will know the treatment allocation and are trained to record allocation and treatment records (timing of device use) and concomitant anti-coagulant medication administered (for example, heparin) on the source documents and case report forms (CRFs) that will be kept blinded from the remaining study personnel.

Nephrology staff will be trained to use the PMX cartridge on those subjects randomized to the treatment

\section{Table 4 Secondary and exploratory outcomes}

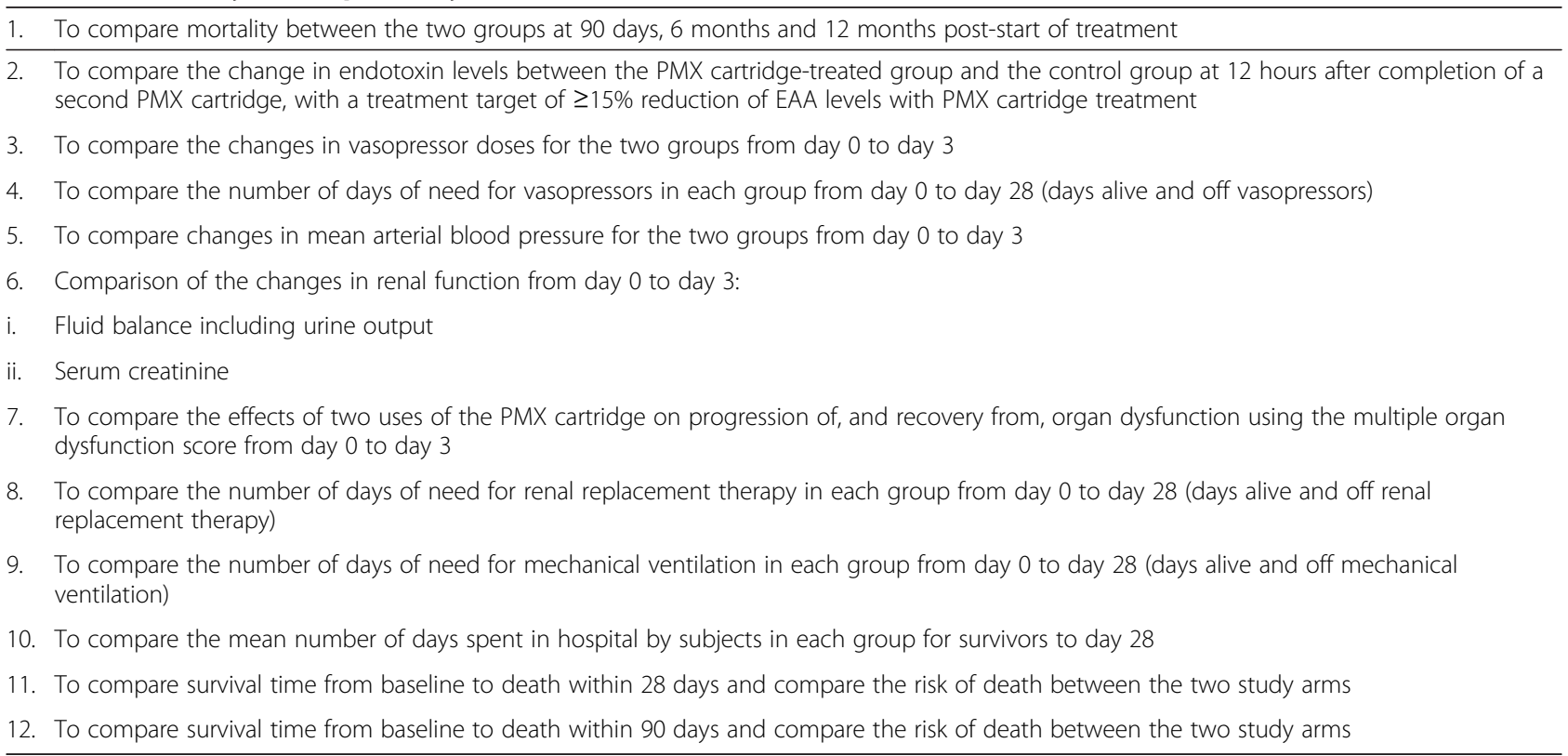




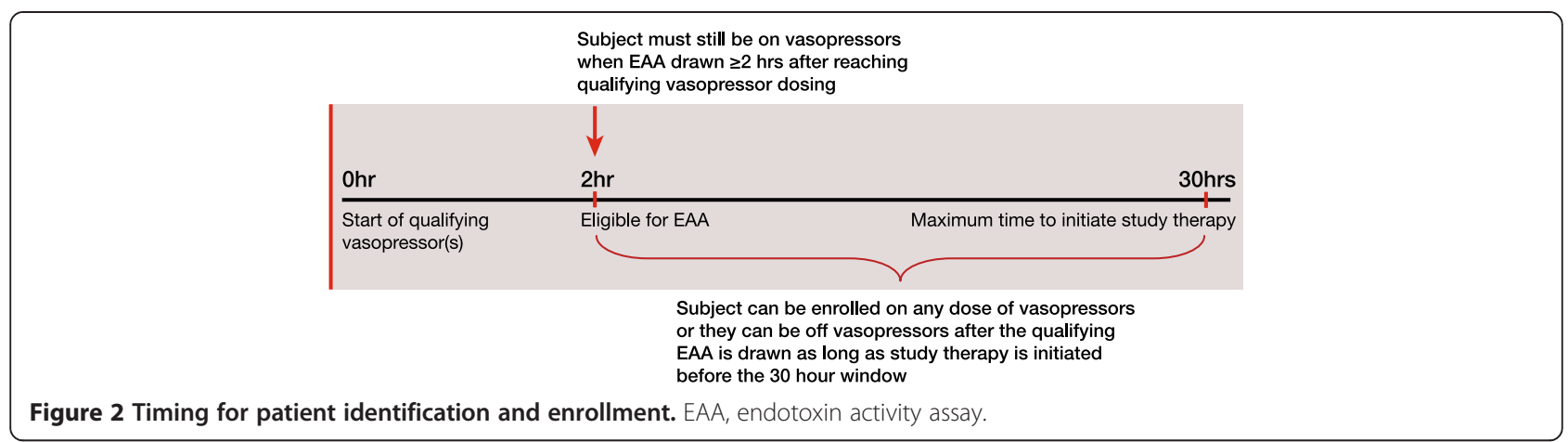

arm and to maintain the blind for the subjects that are randomized to the control arm by performing the "sham" perfusion event. Study staff (principal investigator and other ICU personnel involved in the subjects care) and the subject (and/or the subjects surrogate) will remain blinded to the study allocation. Pre-treatment EAA results will be made available to the treating physician, but all subsequent EAA results are blinded. During the period of time of the treatment intervention or sham perfusion event sites employ a number of methods to ensure the blind is maintained. During the treatment phase, a façade perfusion event is conducted whereby a dialysis instrument is brought to the patient's bedside and curtains are drawn. A sign is attached to the curtain indicating that a study procedure is in progress. The unblinded nephrology team and/or study coordinator perform the hemoperfusion or sham perfusion for approximately 2 hours. This process is repeated once at approximately 22 hours such that the treatment of PMX or sham treatment is completed twice within a 24-hour period.

Breaks in the blind are reported to the sponsor via the medical monitor and are recorded in CRFs. Emergency unblinding procedures include confirmatory correspondence with the pharmacy of the true treatment allocation.

\section{Sample size and power}

The power analysis is based on a two-sided Fisher's exact test to compare the proportions of death within or at 28 days between the PMX treatment and control groups. It is assumed that for the control arm of standard medical care alone approximately $35 \%$ subjects will die by day 28 after the enrollment. It is also hypothesized that there will be an approximately $15 \%$ improvement in 28 -day mortality rate for subjects randomized who receive the standard medical care plus the PMX cartridge, as compared to those receiving the standard medical care alone. The overall significance level for the entire sequence of primary efficacy tests is assumed at $5 \%$ in a two-sided test. An interim analysis based upon safety only was conducted after 76 patients were enrolled in January 2013. No efficacy analysis was conducted. The data safety monitoring board (DSMB) noted no specific safety concerns at that time. There is one planned additional interim analysis approximately at the midpoint (that is, 180 subjects enrolled). Because of the planned interim analysis, the maximum sample size for the trial (that is, if the trial is not terminated by the interim analysis) is based on the final efficacy test to compare day 28 mortality rate between the two study arms at a significance level of 0.048 based on the method of O'Brien and Fleming [28].

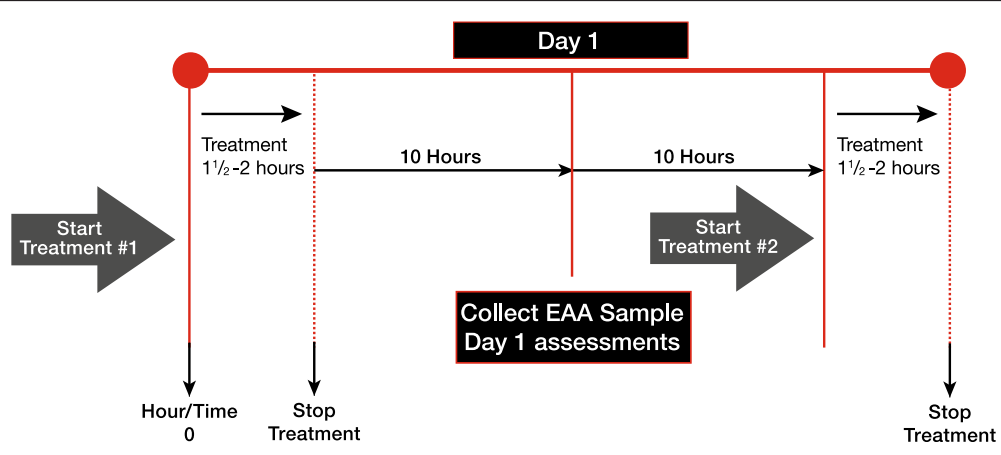

Figure 3 Timeline for initiation of intervention. EAA, endotoxin activity assay. 
Assuming a sample size ratio of 1:1 between the two study arms, a sample of 180 subjects per study arm (that is, a total of 360 subjects for both arms) provides at least $80 \%$ statistical power to detect the hypothesized effect size (that is, $15 \%$ difference) from the final primary efficacy test. The statistical power with the proposed sample size will thus be more than $80 \%$ from the entire sequence of the planned primary efficacy analyses. These power analyses assume a $15 \%$ attrition rate from the randomized subjects of each study arm. Therefore, a minimum of 306 evaluable subjects are necessary to achieve at least $80 \%$ statistical power based on the hypothesized effect size.

\section{Monitoring}

The trial is fully monitored by the contract research organization responsible for trial operations. A trial monitoring plan has been established and is on file with the FDA. One hundred percent source data verification is done for all data points in the CRFs. Protocol violations are predefined. Adherence to treatment as defined by number of treatments delivered versus prescribed as well as total time of each delivered treatment is compiled in the CRF and tabulated for analysis. All co-interventions are captured including concurrent medications. A detailed policy on co-enrollment in other studies has also been developed and approved by the DSMB.

\section{Interim analysis}

An interim analysis will be performed by an unblinded statistician independent of the DSMB and the Sponsor after the first 180 subjects (that is, about 90 per study arm, or about $50 \%$ of the total planned evaluable subjects) complete their day 28 assessment. The interim analysis will only analyze the portion of the data through day 28 for subjects who have completed the day 28 assessment and is based on the final efficacy test to compare day 28 mortality rate between the two study arms at a significance level of 0.048 .

The primary purpose of the interim analysis is to determine if the trial should be terminated early or the study protocol should be modified. The primary population for this interim analysis will be the intention to treat (ITT) population. Secondary analyses will examine the modified ITT population - that is, all patients who have at least one treatment application. The issues to be addressed by the interim analysis will include the possibility that: (a) the treatment is clearly effective so that it is unnecessary to continue to the planned termination point insofar as the primary efficacy endpoint is concerned, $P$ value is less than 0.005 ; or (b) the treatment is so ineffective that continuation of the study would provide little or no chance of ever reaching statistical significance. In addition to the efficacy assessment, at the interim analysis the DSMB will review all serious adverse events and unanticipated serious device effects to evaluate if there are medically significant justifications due to excessive side effects or safety concerns to demand an early end to the trial or a modification of the intervention. The interim analysis will thus evaluate both safety and efficacy variables.

If the trial is not terminated based on the interim analysis, the results of the interim efficacy analysis may be used to revise sample size estimations, which will serve in planning the remaining part of the trial. An independent statistician will conduct the power analyses and sample size re-estimation.

If the trial is terminated as a result of the interim analysis (that is, $P$ value $<0.005$ ) or by the recommendations of the DSMB, the final efficacy and safety analyses will be performed using the entire data of follow-up to 12 months or until the last assessment for all subjects randomized prior to the study termination date.

\section{Statistical analysis of results}

Primary efficacy analyses will be conducted on the ITT population. The primary efficacy endpoint is the allcause mortality rate of the subjects within 28 days after the initiation of the treatment perfusion or the sham perfusion. Let $P_{0}$ and $P_{1}$ be the proportion of death within 28 days for the arm of standard medical care alone and the arm of standard medical care plus the PMX cartridge, respectively. The primary efficacy analyses will test the null hypothesis of $H_{0}: P_{1}=P_{0}$ against the two-sided alternative hypothesis of $H_{a}: P_{1} \neq P_{0}$. The test of these hypotheses will be carried out through Fisher's exact test [29]. A two sided 5\% significance level will be assumed for the primary efficacy test. Similar analyses on the primary efficacy endpoint will also be conducted on the per protocol population.

In addition, a long-term follow-up of survival status at 90 days, 6 months and 12 months will be undertaken for the ITT population. This will entail a comparison of survival rates for ITT subjects at 90 days, 6 months and 12 months after assignment to either the treatment perfusion or the sham control perfusion group.

\section{Safety and the data safety monitoring board}

An external, independent DSMB was established. The DSMB acts in an advisory capacity to the Sponsor to monitor subject safety, including mortality, which is also the primary efficacy endpoint of the intervention. The DSMB comprises a group of individuals with a broad and varied base of pertinent expertise who will review the accumulating safety data on a quarterly basis. The DSMB consists of a microbiologist, a nephrologist, a critical care physician, a biostatistician, and an expert in clinical trial design. The meetings consist of an open 
session blinded report and include participation by the sponsor and their representatives from the clinical research organization trial operations team and a closed session of only DSMB members and one unblinded representative from the $\mathrm{CRO}$. The closed session report of data tables and listings from the database is presented in a blinded manner. The DSMB has the right to ask for unblinding any portion of the closed session report if they deem it necessary. The DSMB will conduct an unblinded interim analysis of the safety data when half of the subjects have completed the first 28 days of the trial. The DSMB will also provide expert opinion on the clinical relevance of any safety findings, address any safety issues mentioned by the sponsor and, where applicable based on the safety data, advise the Sponsor as to the appropriateness of continuing the trial according to the protocol or modifying the protocol. The DSMB may terminate the trial if they deem it necessary for the protection of the safety of potential or current participants.

DSMB members are reimbursed for reasonable expenses related to attending meetings, such as travel costs, accommodations, and meals. Members are compensated for their time spent performing their responsibilities as members of the DSMB. No other payment or future consideration is provided. No formal relationship exists between the DSMB and any other committee involved in the EUPHRATES trial.

\section{Discussion}

There are several unique features of the EUPHRATES trial compared to prior severe sepsis/septic shock studies. The trial does not include an assessment for features of the systemic inflammatory response syndrome as part of standard inclusion criteria. These criteria lack specificity and have been heavily criticized [30]. As an alternative, EUPHRATES targets patients with persistent shock and endotoxemia - aligning the purported mechanism of the treatment effect in hemodynamic improvement and the treatment of the presumed mediator of the disease process.

EUPHRATES is the first clinical trial in septic shock that we are aware of, designed to specifically use a biomarker as enrollment criteria for a therapy directed against that biomarker. This "theragnostic" approach has already proven successful in disease areas such as cancer and offers the opportunity to move beyond the constraints of the syndrome-based definition of sepsis to biologically targeted therapy [4,31]. However, this approach by definition will limit the application of this therapy to only a part of our existing patient population with septic shock and endotoxemia, making the need to search for both new markers and new therapies even more important for those patients who do not have endotoxemia. Nevertheless, the approach may be a better way to conduct sepsis trials using smaller numbers of patients with higher efficacy hurdles. In this trial, if one were to assume that all patients were to be enrolled based on meeting clinical criteria alone and that $50 \%$ of those patients enrolled were not likely to benefit from the treatment, a required efficacy hurdle of $7.5 \%$ would be needed or a trial of nearly 1,200 patients. The duration, cost and complexity of such a trial would likely be prohibitive.

Finally, EUPHRATES is the first trial of a hemoperfusion device to our knowledge that will be blinded. While blinding offers significant advantages in the overall strength of the study, the use of a "sham" perfusion event rather than true sham perfusion was chosen because sham perfusion was felt to be unethical and invasive [32]. Blinding a trial of this nature where patients are unstable and constantly interacting with numerous health-care providers is challenging and it is our intention to study the overall strength of the blinding procedures at the end of this trial so that lessons may be applied to future trials of this nature. This will be done by tracking all unblindings that occur, who was unblinded and how the unblinding occurred.

Thus, EUPHRATES is a pivotal trial using PMX hemoperfusion in patients with septic shock and confirmed endotoxemia. While the results of recent sepsis trials have been disappointing, there are several unique features of EUPHRATES, including its theragnostic design, that we hope are a step forward in the design of clinical trials for this underserved patient population.

\section{Trial status}

The trial, at the time of submission of this manuscript, has enrolled approximately 275 subjects with all anticipated centers activated and trained. The second interim analysis was in the first quarter of 2014. Outcomes included a positive recommendation to continue the trial, sample size recalculation to a new total size of 650 patients, and addition of an exclusion criteria for multiple organ dysfunction score $\leq 9$.

\section{Abbreviations \\ C4: Cooper University Hospital clinical coordinating center; CRF: case report form; DSMB: data safety monitoring board; EAA: endotoxin activity assay; EUPHRATES: Evaluating the Use of Polymyxin B Hemoperfusion in a Randomized controlled trial of Adults Treated for Endotoxemia and Septic shock; FDA: Food and Drug Administration; ITT: intention to treat: LPS: lipopolysaccharide; PMX: Polymyxin B; PMX-DHP: Polymyxin B direct hemoperfusion; SSC: Surviving Sepsis Campaign; TLR: Toll-like receptor.}

\section{Competing interests}

PMW and DF are employees of Spectral Diagnostics Inc. KK is an employee of Amarex, the clinical research organization conducting the trial. DJK has served as a consultant to Spectral Diagnostics Inc. The institutions of RPD and CAS have received research funding and consulting fees (steering committee for trial) from Spectral Diagnostics Inc. 


\section{Authors' contributions}

DJK: conception and design, manuscript writing and final approval of the manuscript. DF: conception and design, manuscript writing and final approval of the manuscript. CAS: conception and design, data collection, manuscript editing and final approval of the manuscript. KK: statistical design, data analysis, manuscript writing and final approval of the manuscript. PMW: conception and design, critical revision of the manuscript and final approval of the manuscript. RPD: conception and design, critical revision of the manuscript, and final approval of the manuscript. All authors agree to be accountable for all aspects of the work.

\section{Acknowledgements}

The authors' wish to acknowledge the members of the steering committee for their guidance and leadership in the EUPHRATES trial. The trial is funded by Spectral Diagnostics Inc., Toronto, Canada. EUPHRATES steering Committee: R Phillip Dellinger, Steven Trzeciak, Christa Schorr (all at Cooper University Hospital, Camden, NJ, USA), John C Marshall (St Michael's Hospital, University of Toronto, Toronto, ON, Canada), Massimo Antonelli (Polyclinico A Gamelli, Rome, Italy), Paul Palevsky (University of Pittsburgh Medical Center, Pittsburgh, PA, USA), and Sean Bagshaw (University of Alberta Hospital, Edmonton, $A B$, Canada).

\section{Author details}

${ }^{1}$ Department of Critical Care, and the Keenan Research Centre, Li Ka Shing Knowledge Institute, 4-054C Donnelly Wing, St Michael's Hospital, 30 Bond Street, Toronto, Ontario M5B 1 W8, Canada. ${ }^{2}$ Spectral Diagnostics Inc., -2 The West Mall, Toronto, Ontario M9C 1C2, Canada. ${ }^{3}$ Cooper University Hospital, Cooper Medical School Rowan University, 1 Cooper Plaza, Camden, NJ 08103, USA. ${ }^{4}$ Amarex Clinical Research, 20201 Century Blvd, 4th Floor, Germantown, MD 20874, USA.

Received: 25 October 2013 Accepted: 14 May 2014

Published: 11 June 2014

\section{References}

1. Hotchkiss RS, Karl IE: The pathophysiology and treatment of sepsis. N Engl J Med 2003, 348:138-150.

2. Angus DC, Linde-Zwirble WT, Lidicker J, Clermont G, Carcillo J, Pinsky MR: Epidemiology of severe sepsis in the United States: analysis of incidence, outcome, and associated costs of care. Crit Care Med 2001, 29:1303-1310.

3. Suffredini AF, Munford RS: Novel therapies for septic shock over the past 4 decades. JAMA 2011, 306:194-199.

4. Angus DC, Mira JP, Vincent JL: Improving clinical trials in the critically ill. Crit Care Med 2010, 38:527-532.

5. Marshall JC, Foster D, Vincent JL, Cook DJ, Cohen J, Dellinger RP, Opal S, Abraham E, Brett SJ, Smith T, Mehta S, Derzko A: Diagnostic and prognostic mplications of endotoxemia in critical illness: results of the MEDIC study. J Infect Dis 2004, 190:527-534.

6. Opal SM, Cohen J: Clinical gram-positive sepsis: does it fundamentally differ from gram-negative bacterial sepsis? Crit Care Med 1999, 27:1608-1616.

7. Klein DJ, Derzko A, Foster D, Seely AJ, Brunet F, Romaschin AD, Marshall JC: Daily variation in endotoxin levels is associated with increased organ failure in critically ill patients. Shock 2007, 28:524-529.

8. Opal SM, Gluck T: Endotoxin as a drug target. Crit Care Med 2003, 31(1 Suppl):S57-S64.

9. Ziegler EJ, McCutchan JA, Fierer J, Glauser MP, Sadoff JC, Douglas H, Braude Al: Treatment of gram-negative bacteremia and shock with human antiserum to a mutant Escherichia coli. N Engl J Med 1982, 307:1225-1230.

10. Greenman RL, Schein RM, Martin MA, Wenzel RP, Maclntyre NR, Emmanuel G, Chmel H, Kohler RB, McCarthy M, Plouffe J, Russell JA, Hollender E, Immerman R, Pfaller M, Sheetz C, Jebson P, Houston A, Rehak D, Empson P, Ireland J, Narain S, Rashkin JE, Jacobs RA, Octavio J, Coleman R, Kenyon VS, Yangco BG, Toney JF, Edwards J, Crislip M, et al: A controlled clinical trial of E5 murine monoclonal $\operatorname{lgM}$ antibody to endotoxin in the treatment of gram-negative sepsis. The XOMA Sepsis Study Group. JAMA 1991, 266:1097-1102.

11. Ziegler EJ, Fisher CJ Jr, Sprung CL, Straube RC, Sadoff JC, Foulke GE, Wortel $\mathrm{CH}$, Fink MP, Dellinger RP, Teng NN, Allen E, Berger $\mathrm{HJ}$, Knatterud $\mathrm{GL}$, LoBuglio AF, Smith CR, and the HA-1A Sepsis Study Group: Treatment of gram-negative bacteremia and septic shock with HA-1A human monoclonal antibody against endotoxin. A randomized, double-blind, placebo-controlled trial. The HA-1A Sepsis Study Group. N Engl J Med 1991, 324:429-436.

12. McCloskey RV, Straube RC, Sanders C, Smith SM, Smith CR: Treatment of septic shock with human monoclonal antibody HA-1A. A randomized, double-blind, placebo-controlled trial. CHESS Trial Study Group. Ann Intern Med 1994, 121:1-5.

13. Angus DC, Birmingham MC, Balk RA, Scannon PJ, Collins D, Kruse JA, Graham DR, Dedhia HV, Homann S, Maclntyre N: E5 murine monoclonal antiendotoxin antibody in gram-negative sepsis: a randomized controlled trial. E5 Study Investigators. JAMA 2000, 283:1723-1730.

14. Rice TW, Wheeler AP, Bernard GR, Vincent JL, Angus DC, Aikawa N, Demeyer I, Sainati S, Amlot N, Cao C, li M, Matsuda H, Mouri K, Cohen J: A randomized, double-blind, placebo-controlled trial of TAK-242 for the treatment of severe sepsis. Critl Care Med 2010, 38:1685-1694.

15. Opal SM, Laterre PF, Francois B, LaRosa SP, Angus DC, Mira JP, Wittebole X, Dugernier T, Perrotin D, Tidswell M, Jauregui L, Krell K, Pachl J, Takahashi T, Peckelsen C, Cordasco E, Chang CS, Oeyen S, Aikawa N, Maruyama T, Schein R, Kalil AC, Van Nuffelen M, Lynn M, Rossignol DP, Gogate J, Roberts MB, Wheeler $J$, Vincent $J L$, for the ACCESS Study Group: Effect of eritoran, an antagonist of MD2-TLR4, on mortality in patients with severe sepsis: the ACCESS randomized trial. JAMA 2013, 309:1154-1162.

16. Dellinger RP, Tomayko JF, Angus DC, Opal S, Cupo MA, McDermott S, Ducher A, Calandra T, Cohen J, for the Lipid Infusion and Patient Outcomes in Sepsis (LIPOS) Investigators: Efficacy and safety of a phospholipid emulsion (GR270773) in Gram-negative severe sepsis: results of a phase II multicenter, randomized, placebo-controlled, dose-finding clinical trial. Crit Care Med 2009, 37:2929-2938.

17. Davies B, Cohen J: Endotoxin removal devices for the treatment of sepsis and septic shock. Lancet Infect Dis 2011, 11:65-71.

18. Cruz D, Perazella M, Bellomo R, de Cal M, Polanco N, Corradi V, Lentini P, Nalesso F, Ueno T, Ranieri V, Ronco C: Effectiveness of polymyxin Bimmobilized fiber column in sepsis: a systematic review. Crit Care 2007, 11:1-12.

19. Cruz DN, Antonelli M, Fumagalli R, Foltran F, Brienza N, Donati A, Malcangi V, Petrini F, Volta G, Bobbio Pallavicini FM, Rottoli F, Giunta F, Ronco C: Early use of polymyxin $B$ hemoperfusion in abdominal septic shock: the EUPHAS randomized controlled trial. JAMA 2009, 301:2445-2452.

20. Kellum JA, Uchino S: International differences in the treatment of sepsis: are they justified? JAMA 2009, 301:2496-2497.

21. Arnold RC, Shapiro NI, Jones AE, Schorr C, Pope J, Casner E, Parrillo JE, Dellinger RP: Multi-center study of early lactate clearance as a determinant of survival in patients with presumed Sspsis. Shock 2008, 32:35-39.

22. Cook R, Cook D, Tilley J, Lee K, Marshall J, Canadian Critical Care Trials Group: Multiple organ dysfunction: baseline and serial component scores. Crit Care Med 2001, 29:2046-2050.

23. Warnock DG: Towards a definition and classification of acute kidney injury. J Am Soc Nephrol 2005, 16:3149-3150.

24. Levy MM, ellinger RP, Townsend SR, Linde-Zwirble WT, Marshall JC, Bion J, Schorr C, Artigas A, Ramsay G, Beale R, Parker MM, Gerlach H, Reinhart K, Silva E, Harvey M, Regan S, Angus DC, Surviving Sepsis Campaign: The Surviving Sepsis Campaign: results of an international guideline-based performance improvement program targeting severe sepsis. Crit Care Med 2010, 38:367-374

25. Dellinger RP, Levy MM, Carlet JM, Bion J, Parker MM, Jaeschke R, Reinhart K, Angus DC, Brun-Buisson C, Beale R, Calandra T, Dhainaut JF, Gerlach H, Harvey M, Marini JJ, Marshall J, Ranieri M, Ramsay G, Sevransky J, Thompson BT, Townsend S, Vender JS, Zimmerman JL, Vincent JL, International Surviving Sepsis Campaign Guidelines Committee; American Association of Critical-Care Nurses; American College of Chest Physicians; American College of Emergency Physicians; Canadian Critical Care Society; European Society of Clinical Microbiology and Infectious Diseases; European Society of Intensive Care Medicine; European Respiratory Society; International Sepsis Forum; Japanese Association for Acute Medicine; Japanese Society of Intensive Care Medicine; Society of Critical Care Medicine; Society of Hospital Medicine; Surgical Infection Society; World Federation of Societies of Intensive and Critical Care Medicine: Surviving Sepsis Campaign: international guidelines for management of severe sepsis and septic shock: 2008. Crit Care Med 2008, 36:296-327.

26. Dellinger RP, Levy MM, Rhodes A, Annane D, Gerlach H, Opal SM, Sevransky JE, Sprung CL, Douglas IS, Jaeschke R, Osborn TM, Nunnally ME, Townsend SR, 
Reinhart K, Kleinpell RM, Angus DC, Deutschman CS, Machado FR, Rubenfeld GD, Webb S, Beale RJ, Vincent JL, Moreno R, Surviving Sepsis Campaign Guidelines Committee including The Pediatric Subgroup: Surviving sepsis campaign: international guidelines for management of severe sepsis and septic shock: 2012. Crit Care Med 2013, 41:580-637.

27. Marshall JC, Walker PM, Foster DM, Harris D, Ribeiro M, Paice J, Romaschin AD, Derzko AN: Measurement of endotoxin activity in critically ill patients using whole blood neutrophil dependent chemiluminescence. Crit Care 2002, 6:342-348

28. O'Brien PC, Fleming TR: A multiple testing procedure for clinical trials. Biometrics 1979, 35:549-556.

29. Agresti A: Categorical Data Analysis. New York: Wiley; 1990.

30. Vincent JL: Dear SIRS, I'm sorry to say that I don't like you. Crit Care Med 1997, 25:372-374.

31. Fdr P, Courtine E, Cariou A, Mira J-P: Toward theragnostics. Crit Care Med 2009, 37:S50-S58.

32. Macklin R: The ethical problems with sham surgery in clinical research. N Engl J Med 1999, 341:992-996.

doi:10.1186/1745-6215-15-218

Cite this article as: Klein et al.: The EUPHRATES trial (Evaluating the Use of Polymyxin B Hemoperfusion in a Randomized controlled trial of Adults Treated for Endotoxemia and Septic shock): study protocol for a randomized controlled trial. Trials 2014 15:218.

\section{Submit your next manuscript to BioMed Central and take full advantage of:}

- Convenient online submission

- Thorough peer review

- No space constraints or color figure charges

- Immediate publication on acceptance

- Inclusion in PubMed, CAS, Scopus and Google Scholar

- Research which is freely available for redistribution 